\title{
Drug Experience Epigenetically Primes Fosb Gene Inducibility in Rat Nucleus Accumbens
}

\author{
Diane Damez-Werno, ${ }^{1 \star}$ Quincey LaPlant, ${ }^{1 \star}$ HaoSheng Sun, ${ }^{1}$ Kimberly N. Scobie, ${ }^{1}$ David M. Dietz, ${ }^{1}$ Ian M. Walker, ${ }^{2}$ \\ Ja Wook Koo, ${ }^{1}$ Vincent F. Vialou, ${ }^{1}$ Ezekiell Mouzon, ${ }^{1}$ Scott J. Russo, ${ }^{1}$ and Eric J. Nestler ${ }^{1}$ \\ ${ }^{1}$ Fishberg Department of Neuroscience and Friedman Brain Institute, Mount Sinai School of Medicine, New York, New York 10029, and ${ }^{2}$ Department of \\ Psychiatry, University of Texas Southwestern Medical Center, Dallas, Texas 75390
}

\begin{abstract}
$\Delta$ FosB, a Fosb gene product, is induced in nucleus accumbens (NAc) and caudate-putamen (CPu) by repeated exposure to drugs of abuse such as cocaine. This induction contributes to aberrant patterns of gene expression and behavioral abnormalities seen with repeated drug exposure. Here, we assessed whether a remote history of cocaine exposure in rats might alter inducibility of the Fosb gene elicited by subsequent drug exposure. We show that prior chronic cocaine administration, followed by extended withdrawal, increases inducibility of Fos $b$ in NAc, as evidenced by greater acute induction of $\Delta$ FosB mRNA and faster accumulation of $\Delta$ FosB protein after repeated cocaine reexposure. No such primed Fosb induction was observed in $\mathrm{CPu}$; in fact, subsequent acute induction of $\Delta$ FosB mRNA was suppressed in $\mathrm{CPu}$. These abnormal patterns of Fosb expression are associated with chromatin modifications at the Fosb gene promoter. Prior chronic cocaine administration induces a long-lasting increase in RNA polymerase II (Pol II) binding at the Fosb promoter in NAc only, suggesting that Pol II "stalling" primes Fosb for induction in this region upon reexposure to cocaine. A cocaine challenge then triggers the release of Pol II from the gene promoter, allowing for more rapid Fosb transcription. A cocaine challenge also decreases repressive histone modifications at the Fosb promoter in NAc, but increases such repressive marks and decreases activating marks in CPu. These results provide new insight into the chromatin dynamics at the Fosb promoter and reveal a novel mechanism for primed Fosb induction in NAc upon reexposure to cocaine.
\end{abstract}

\section{Introduction}

Drug addiction is characterized by compulsive drug seeking and taking despite severe adverse consequences (Kalivas et al., 2005; Hyman et al., 2006). Chronic drug exposure causes persistent changes in gene expression in ventral striatum [or nucleus accumbens (NAc)] and dorsal striatum [or caudate-putamen $(\mathrm{CPu})]$, striatal structures implicated in drug reward and addiction (Freeman et al., 2001; Robinson and Kolb, 2004; Shaham and Hope, 2005; Maze and Nestler, 2011). $\Delta$ FosB, a truncated and stable protein encoded by the immediate-early gene, Fosb, is a well characterized transcription factor induced in NAc and $\mathrm{CPu}$ by chronic exposure to virtually all drugs of abuse, where it mediates sensitized behavioral responses to repeated drug administration (Nestler, 2008). However, whether prior chronic exposure to a drug of abuse alters subsequent induction of $\Delta$ FosB remains unknown.

We hypothesized recently that chromatin modifications in response to chronic drug exposure might alter the inducibility

\footnotetext{
Received March 15, 2012; revised May 19, 2012; accepted June 2, 2012.

Author contributions: D.D.-W., Q.L., H.S., D.M.D., S.J.R., and E.J.N. designed research; D.D.-W., Q.L., H.S., K.N.S., D.M.D., I.M.W., J.W.K., V.F.V., E.M., and S.J.R. performed research; D.D.-W., Q.L., I.M.W., and S.J.R. analyzed data; D.D.-W., Q.L., H.S., K.N.S., and E.J.N. wrote the paper.

This work was supported by grants from the National Institute on Drug Abuse.

${ }^{*}$ D.D.-W. and Q.L. contributed equally to this work.

Correspondence should be addressed to Eric J. Nestler, Fishberg Department of Neuroscience, Mount Sinai School of Medicine, One Gustave L. Levy Place, Box 1065, New York, NY 10029. E-mail: eric.nestler@mssm.edu.

DOI:10.1523/JNEUROSCI.1290-12.2012

Copyright $\odot 2012$ the authors $\quad 0270-6474 / 12 / 3210267-06 \$ 15.00 / 0$
}

of specific genes in target brain regions (Robison and Nestler, 2011). Increasing evidence has shown that drugs of abuse after chronic administration alter the structure and transcriptional accessibility of chromatin through numerous types of modifications, including phosphorylation, acetylation, and methylation of histone tails. Recent work in cell culture systems has focused on the recruitment of RNA polymerase II (Pol II) to the promoter of inducible genes before their expression, with Pol II bound persistently to proximal promoter regions and around the transcription start site (TSS) in a stalled state (Core and Lis, 2008; Nechaev and Adelman, 2008). Activation of the stalled Pol II is then thought to be responsible for its escape from promoter and TSS regions and its transcription of these primed genes (Zeitlinger et al., 2007; Saha et al., 2011; Bataille et al., 2012).

Here, we show that prior chronic exposure to cocaine, followed by an extended withdrawal period, alters the induciblity of the Fosb gene to subsequent cocaine administration, with NAc being primed for induction while $\mathrm{CPu}$ is not. We then identify distinct chromatin signatures at the Fosb gene promoter in NAc and $\mathrm{CPu}$ that are associated with such aberrant inducibility of the Fosb gene, including the recruitment of stalled Pol II at the Fosb proximal promoter in NAc only, as well as changes in several activating or repressive histone modifications in both brain regions. These results provide novel insight into the chromatin dynamics at the Fosb gene promoter and indicate for the first time a mechanism by which stalling of Pol II primes Fosb for greater activation in NAc upon reexposure to cocaine. 
A
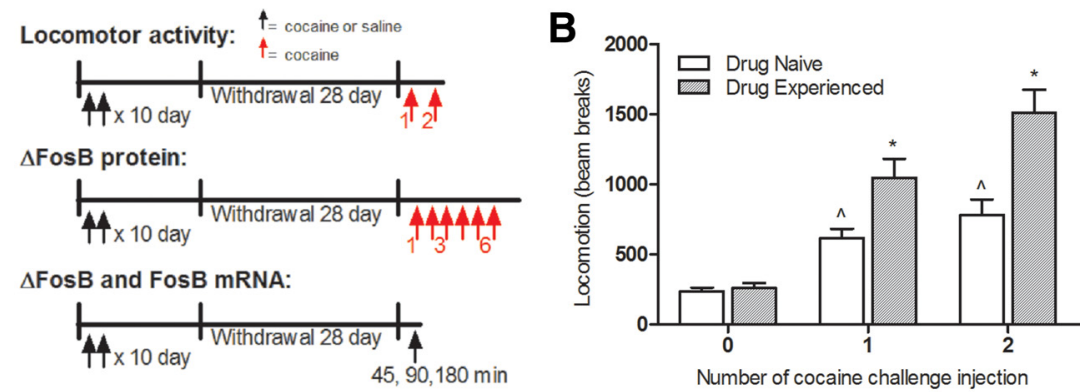

C
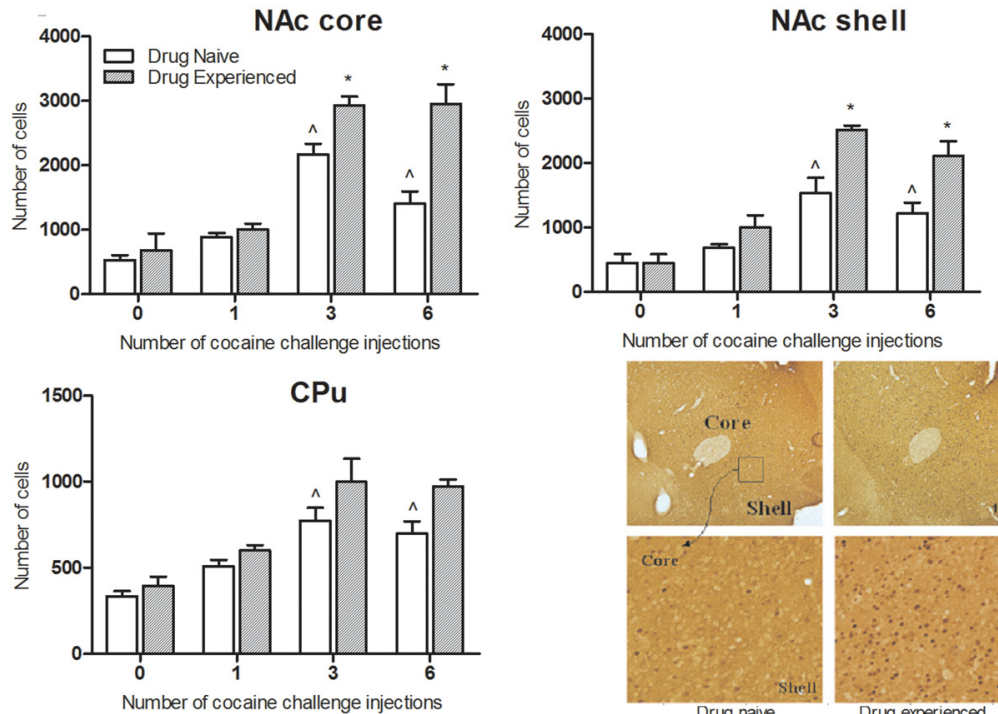

D
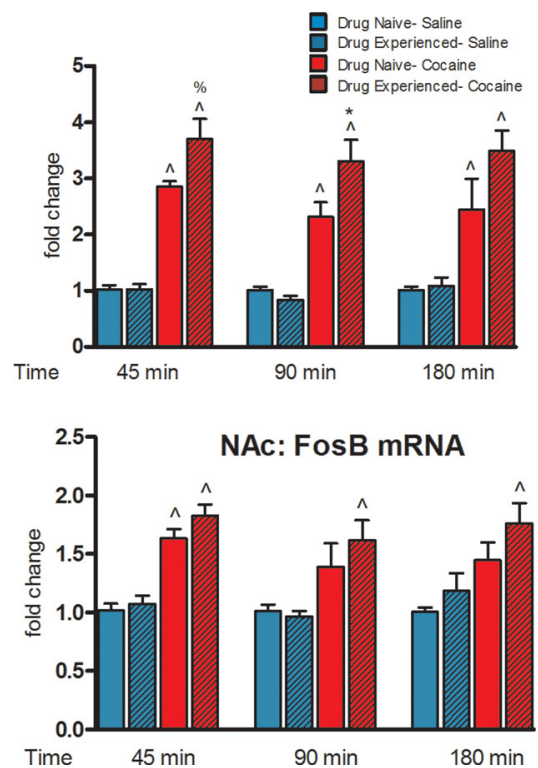

Number of cocaine challenge injections
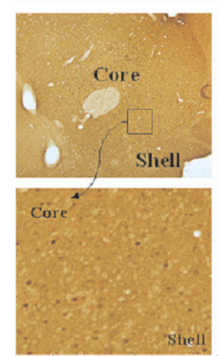

Drug naive
(3 injections)

CPu: $\triangle$ FosB mRNA
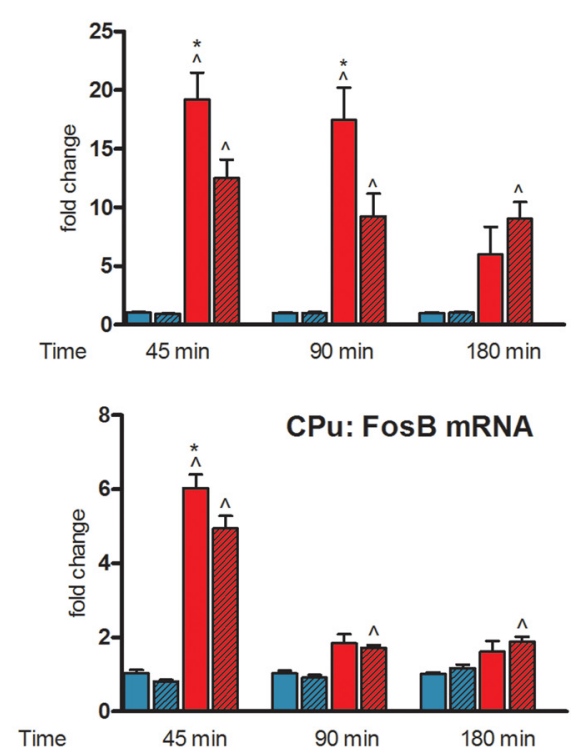

Figure 1. Effect of prior chronic cocaine exposure on locomotor activity and Fosb induction in NAc and CPu upon reexposure to the drug. $A$, Rats were injected intraperitoneally twice daily with either saline (Drug Naive) or cocaine (15 mg/kg; Drug Experienced) for $10 \mathrm{~d}$ and, after $28 \mathrm{~d}$ of withdrawal, were treated with one ( $\triangle \mathrm{FosB}$ and FosB mRNA) or several (Locomotor activity; $\Delta \mathrm{Fos} B$ protein) challenge injections of cocaine ( $15 \mathrm{mg} / \mathrm{kg}$, i.p). $\boldsymbol{B}$, Animals were habituated in a locomotor chamber without any challenge injection for $1 \mathrm{~h}$, and then monitored for locomotor activity after one saline injection (Injection $0, n=16$ ) or cocaine challenge injections (Injection 1, $n=12$; Injection 2, $n=8$ ). Data are expressed as sum of total number of beam breaks over 60 min after the saline or cocaine injection. C, After $28 \mathrm{~d}$ of withdrawal, cocaine-naive and -experienced rats were injected intraperitoneally once with saline (Injection $0, n=3$ ) and with 1,3, or 6 cocaine challenge injections ( $n=5$ per group). Animals were killed $24 \mathrm{~h}$ after the last injection and $\Delta$ FosB protein was quantified immunohistochemically in NAc and CPu. Bonferroni posttests: $\wedge p<0.001(\boldsymbol{B})$, $p<0.05$ (C), different from Drug Naive with no cocaine challenge; ${ }^{*} p<0.001(\boldsymbol{B}), p<0.05(\boldsymbol{C})$, different from Drug Naive with cocaine challenges. Images displayed are from NAc shell. $\boldsymbol{D}$, Animals were killed 45,90 , or $180 \mathrm{~min}$ after a single saline or cocaine

\section{Materials and Methods}

Animals. Male Sprague Dawley rats (250-275 g; Charles River Laboratories), used in all experiments, were pair-housed in a climatecontrolled room on a $12 \mathrm{~h}$ light/dark cycle (lights on at 7:00 A.M.) with access to food and water ad libitum. All animals were injected twice a day for $10 \mathrm{~d}$ with cocaine $(15 \mathrm{mg} / \mathrm{kg}$, i.p.) or saline (i.p.) in their home cages. Animal experiments were approved by the Institutional Animal Care and Use Committee at Mount Sinai.

Locomotor measurements. Animals were habituated in the locomotor chamber the first day for $1 \mathrm{~h}$, and then monitored for locomotor activity after a saline injection using the Photobeam Activity System (San Diego Instruments). After $1 \mathrm{~h}$ habituation in the locomotor chambers each day, cocaine $(15 \mathrm{mg} / \mathrm{kg}$, i.p.) was administered daily for $2 \mathrm{~d}$ and animals were again monitored for locomotor activity for $1 \mathrm{~h}$.

Immunohistochemistry. Animals were perfused $24 \mathrm{~h}$ after their last drug exposure. $\Delta$ FosB/FosB immunoreactivity was detected as described previously (Perrotti et al., 2004). Western blotting confirmed that all of the $\Delta$ FosB/FosB-like immunoreactivity observed $24 \mathrm{~h}$ or longer after cocaine injections reflected $\Delta$ FosB, with FosB being undetectable (data not shown).

RNA isolation, reverse transcription, and PCR. Bilateral 12-gauge punches of NAc and dorsolateral/dorsomedial $\mathrm{CPu}$ were obtained as described previously (Perrotti et al., 2004), frozen on dry ice, and processed according to published protocols (Covington et al., 2011). $\Delta$ FosB and FosB mRNA was measured using quantitative PCR (qPCR) with isoformspecific $\triangle$ FosB and FosB primers (Alibhai et al., 2007). $\Delta$ FosB and FosB mRNA levels were normalized to GAPDH mRNA levels, which were not affected by cocaine exposure (data not shown).

Western blotting. NAc and $\mathrm{CPu}$ punches were collected as above and processed for Western blotting as described previously (Covington et al., 2011) using antibodies against ERK44/42 (extracellular signal regulated kinase-44/42) and phosphoERK44/42 (pERK), AKT (thymoma viral proto-oncogene) and p-AKT, SRF (serum response factor) and pSRF, and CREB (cAMP response element binding protein) and PCREB. The amount of protein blotted onto each lane was normalized to levels of actin or tubulin, which were unaffected by cocaine exposure.

Chromatin immunoprecipitation. Freshly dissected NAc and $\mathrm{CPu}$ punches were prepared for chromatin immunoprecipitation (ChIP) as described previously (Maze et al., 2010). Each

challenge ( $n=7$ per group). Bonferroni posttests: $\wedge p<0.05$, different from Drug Naive-Saline; ${ }^{*} p<0.05,{ }^{\%} p=0.08$, different from Drug Naive-Cocaine. Data are expressed as mean \pm SEM. 
A
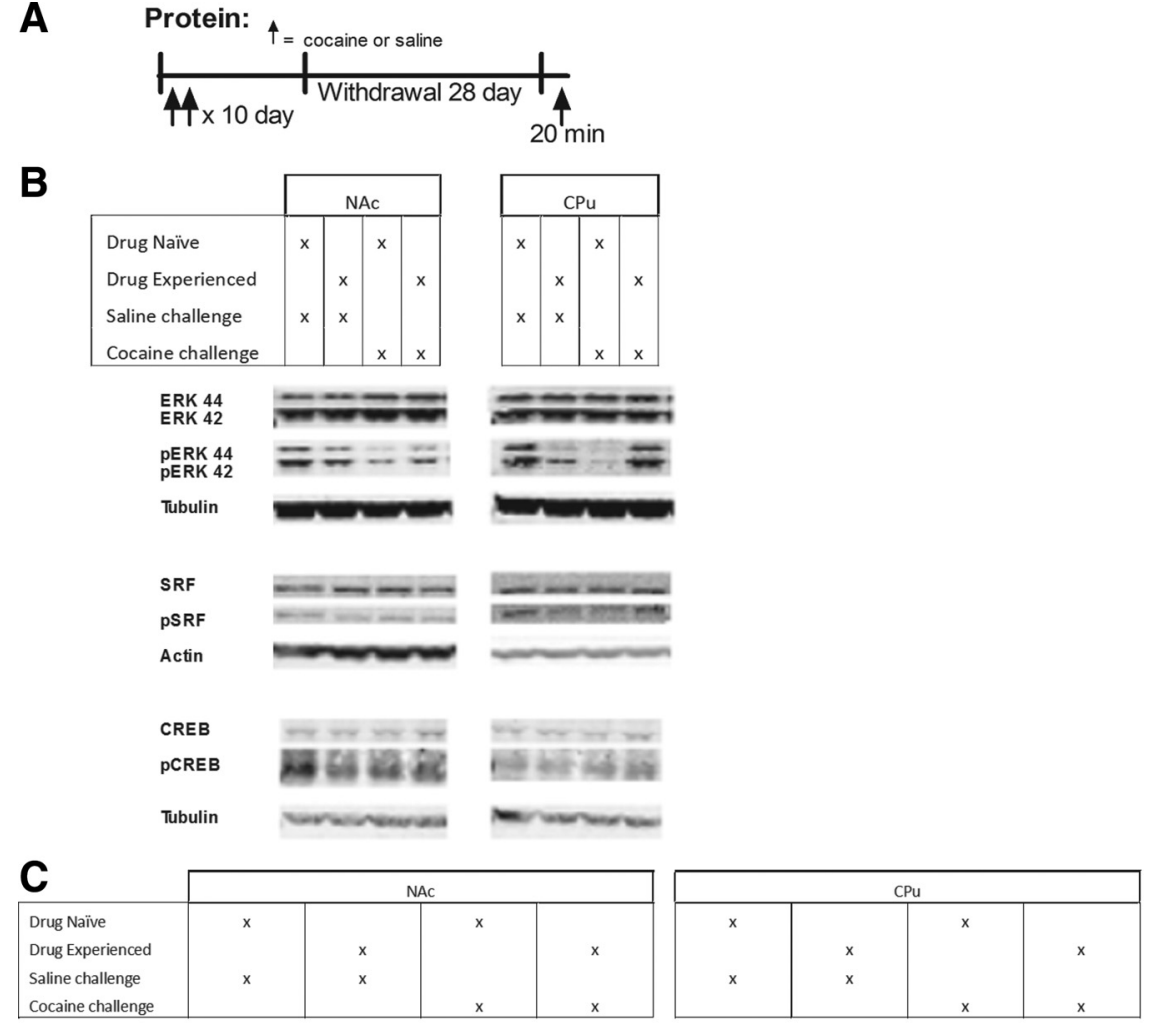

\begin{tabular}{|l|cc|cc|cc|cc|}
\cline { 2 - 8 } \multicolumn{1}{c|}{} & Mean & sem & Mean & sem & Mean & sem & Mean & sem \\
\hline ERK42 & 1 & 0.07 & 1.03 & 0.09 & 1.03 & 0.08 & 1.05 & 0.11 \\
pERK42 & 1 & 0.05 & 0.89 & 0.11 & $\underline{\mathbf{0 . 6 3}}$ & 0.08 & 0.90 & 0.10 \\
pERK42/ERK42 & 1 & 0.05 & 0.87 & 0.11 & $\underline{\mathbf{0 . 6 0}}$ & 0.07 & 0.87 & 0.11 \\
\hline \hline
\end{tabular}

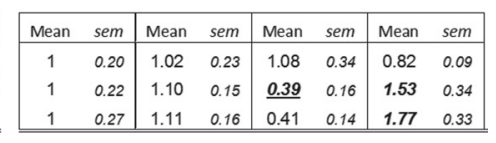

\begin{tabular}{|l|ll|ll|ll|ll|}
\hline ERK44 & 1 & 0.09 & 1.04 & 0.12 & 1.08 & 0.10 & 1.22 & 0.20 \\
PERK44 & 1 & 0.06 & 0.80 & 0.13 & $\underline{\underline{0.59}}$ & 0.14 & 0.90 & 0.14 \\
pERK44/ERK44 & 1 & 0.10 & 0.78 & 0.15 & $\underline{\underline{0.55}}$ & 0.15 & 0.72 & 0.06 \\
\hline
\end{tabular}

\begin{tabular}{|l|ll|ll|ll|ll|}
\hline SRF & 1 & 0.05 & 0.88 & 0.11 & 0.97 & 0.05 & 0.88 & 0.10 \\
PSRF & 1 & 0.11 & 0.92 & 0.11 & 0.88 & 0.07 & 0.93 & 0.14 \\
pSRF/SRF & 1 & 0.14 & 0.91 & 0.12 & 0.89 & 0.10 & 1.14 & 0.23 \\
\hline
\end{tabular}

\begin{tabular}{|l|ll|ll|ll|ll|}
\hline AKT & 1 & 0.05 & 1.00 & 0.04 & 1.05 & 0.02 & 1.03 & 0.04 \\
PAKT & 1 & 0.03 & 0.84 & 0.18 & 1.10 & 0.11 & 1.12 & 0.06 \\
PAKT/AKT & 1 & 0.06 & 0.96 & 0.05 & 1.01 & 0.10 & 1.06 & 0.04 \\
\hline \hline
\end{tabular}

\begin{tabular}{|l|ll|ll|ll|ll|}
\hline CREB & $\mathbf{1}$ & 0.10 & 1.01 & 0.09 & 1.17 & 0.18 & 1.12 & 0.09 \\
PCREB & $\mathbf{1}$ & 0.12 & 0.85 & 0.09 & 0.98 & 0.22 & 1.18 & 0.17 \\
pCREB/CREB & $\mathbf{1}$ & 0.19 & 0.81 & 0.11 & 0.75 & 0.12 & 0.98 & 0.20 \\
\hline
\end{tabular}

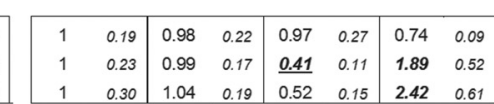

\begin{tabular}{|ll|ll|ll|ll|}
\hline 1 & 0.10 & 1.19 & 0.12 & 1.14 & 0.11 & 0.88 & 0.14 \\
1 & 0.27 & 1.22 & 0.18 & 0.79 & 0.11 & 1.02 & 0.14 \\
1 & 0.30 & 1.03 & 0.16 & 0.72 & 0.12 & 1.17 & 0.12 \\
\hline \hline
\end{tabular}

Figure 2. Effect of prior chronic cocaine exposure on upstream molecular signaling cascades in NAc and CPu. $\boldsymbol{A}$, Rats were injected intraperitoneally twice daily with either saline (Drug Naive) or cocaine ( $15 \mathrm{mg} / \mathrm{kg}$; Drug Experienced) for $10 \mathrm{~d}$. After $28 \mathrm{~d}$ of withdrawal, animals were given one injection of saline or cocaine (15 mg/kg, i.p.) and killed $20 \mathrm{~min}$ later to collect NAc and CPu for Western blotting of $\boldsymbol{B}$, SRF, pSRF, and pSRF/SRF; CREB, pCREB, and pCREB/CREB; ERK42, pERK42, pERK42/ ERK42, ERK44, pERK44, and pERK44/ERK44; and AKT, pAKT, and pAKT/AKT, which were analyzed and presented as $\boldsymbol{C}$, mean \pm SEM of protein fold change compared with Drug Naive Saline-treated animals $n=6$ per group. Two-tailed Student's $t$ test, $p<0.05$. Bold italic highlights significant changes; underlined $=$ decreases; not underlined $=$ increases.

experimental condition was analyzed in triplicate from independent groups of animals. For each ChIP sample, bilateral NAc and $\mathrm{CPu}$ punches were pooled from five rats ( 10 punches). The antibodies used for specific histone modifications are the same those previously published (Maze et al., 2010); antibodies to Pol II phosphorylated at Ser5 of its C terminal domain (CTD) repeat region (Pol II-pSer5) was obtained from abcam 5131. Four sets of ChIP primers were designed for Fosb (Lazo et al., 1992; Mandelzys et al., 1997): 1 forward: GTACAGCGGAGGTCTGAAGG, 1 reverse: GAGTGGGATGAGATGCGAGT; 2 forward: CATCCCACTCGGCCATAG, 2 reverse: CCACCGAAGACAGGTACTGAG; 3 forward: GCTGCCTTTAGCCAATCAAC, 3 reverse: CCAGGTCCAAAGAAAGTCCTC; 4 forward: GGGTGTTTGTGTGTGAGTGG, 4 reverse: AGAGGAGGCTG-
GACAGAACC. Levels of chromatin modifications are compared with those for input DNA as described previously (Maze et al., 2010).

Statistical analysis. All values reported are mean \pm SEM. Data for locomotor activity and cell-counting were analyzed by two-way ANOVAs with treatment and injection as factors. qPCR experiments were analyzed per time point by one-way ANOVAs with treatment as a factor. When significant main effects were observed $(p<0.05)$, Bonferroni post hoc tests were conducted for comparisons to drug-naive saline-treated animals and drug-naive cocaine-treated animals. Unpaired two-tailed Student's $t$ tests were used for Western blotting and ChIP data, with corrections for multiple comparisons.

\section{Results}

Greater Fosb inducibility in NAc, but not $\mathrm{CPu}$, of cocaine-experienced rats

To examine the influence of a prior chronic course of cocaine, followed by a prolonged period of withdrawal, on inducibility of the Fosb gene in response to a subsequent cocaine challenge, rats that were previously injected intraperitoneally twice daily with saline or cocaine $(15 \mathrm{mg} /$ $\mathrm{kg}$, i.p.) for $10 \mathrm{~d}$ were given challenge doses of the drug after $28 \mathrm{~d}$ of withdrawal (Fig. 1A). We first measured locomotor responses in one group of animals to confirm the induction of locomotor sensitization by prior cocaine exposure, an expected lasting consequence of drug administration. Cocaine-experienced and -naive rats showed equivalent baseline locomotor activity, with a cocaine challenge to drugnaive animals increasing their locomotion (repeated-measures two-way ANOVA, treatment: $F_{(1,66)}=30.42, p<0.0001$; cocaine challenge: $F_{(2,66)}=58.39, p<$ 0.0001 ; treatment $\times$ cocaine challenge: $F_{(2,66)}=8.56, p=0.0005$, Bonferroni posttests, $p<0.001$; Fig. $1 B$ ). This cocaine challenge induced significantly greater locomotor activity, i.e., sensitization, in cocaine-experienced rats (Bonferroni posttests, $p<0.001$ ).

To evaluate the effects of this cocainepretreatment regimen on $\Delta$ FosB expression in $\mathrm{NAc}$ and $\mathrm{CPu}$, we measured $\triangle \mathrm{FosB}$ protein with immunohistochemical methods $24 \mathrm{~h}$ after cocaine-naive and cocaine-experienced animals were treated with $0,1,3$, or 6 daily cocaine challenge injections (15 mg/kg; Fig. 1A). As previously established (Nye et al., 1995), three cocaine injections were sufficient to significantly induce $\triangle \mathrm{FosB}$ protein in $\mathrm{NAc}$ and $\mathrm{CPu}$ of drug-naive animals and its accumulation remained significant after $6 \mathrm{~d}$ of cocaine injections (repeated-measures two-way ANOVA, NAc core, treatment: $F_{(1,28)}=23.5, p<0.0001$; cocaine challenge: $F_{(3,28)}=49.16, p<$ 0.0001 ; treatment $\times$ cocaine challenge: $F_{(3,28)}=6.83, p=0.0014$; NAc shell, treatment: $F_{(1,28)}=18.69, p<0.0001$; cocaine chal- 
lenge: $F_{(3,28)}=31.52, p<0.0001$; treatment $\times$ cocaine challenge: $F_{(3,28)}=3.21$, $p<0.05 ; \mathrm{CPu}$, treatment: $F_{(1,28)}=9.47$, $p<0.001$; cocaine challenge: $F_{(3,28)}=$ $19.74, p<0.0001$; treatment $\times$ cocaine challenge: $F_{(3,28)}=0.94, p>0.05$; in NAc core, shell, and $\mathrm{CPu}$, Bonferroni posttests: $p<0.05)$. In cocaine-experienced animals, there was no evidence of persisting $\Delta$ FosB induction in NAc or CPu after $28 \mathrm{~d}$ of withdrawal, consistent with prior reports that the $\Delta$ FosB signal fully dissipates by this time point (Nye et al., 1995), which is the reason this time point was used in this study. Strikingly, however, cocaineexperienced rats that received three or six cocaine challenge injections showed significantly greater $\Delta$ FosB protein induction in NAc, an effect apparent in both core and shell subregions (Bonferroni posttests: $p<0.05$; Fig. $1 C$ ). In contrast, no such greater induction of $\Delta$ FosB protein was observed in $\mathrm{CPu}$; instead, equivalent $\Delta$ FosB induction was seen in this region after 3 or $6 \mathrm{~d}$ of cocaine challenge injections in cocaine-naive and -experienced rats (Fig. 1C).

To gain insight into the transcriptional alterations occurring in NAc and $\mathrm{CPu}$ in response to a cocaine challenge, we studied the time course $(45,90$, and $180 \mathrm{~min})$ of the inducibility of $\Delta$ FosB and FosB mRNA transcripts upon a single cocaine or saline injection given to cocaine-naive and -experienced rats after $28 \mathrm{~d}$ of withdrawal (Fig. 1A). Relative to a saline challenge, a cocaine challenge induced a rapid increase in $\triangle$ FosB and FosB mRNA levels at all three time points in both NAc and $\mathrm{CPu}$ of cocaine-naive animals (repeatedmeasures one-way ANOVA per time point; Bonferroni posttests: $p<0.05$; Fig. $1 D)$. In NAc, we observed greater $\Delta$ FosB and FosB mRNA induction in cocaineexperienced animals compared with cocaine-naive animals after the cocaine challenge, the effect being significant at 90 min while, in contrast, the inducibility of $\Delta$ FosB and FosB mRNA in CPu was significantly decreased in cocaine-experienced animals (Bonferroni posttests: $p=0.08, p<$ 0.05; Fig. 1D).
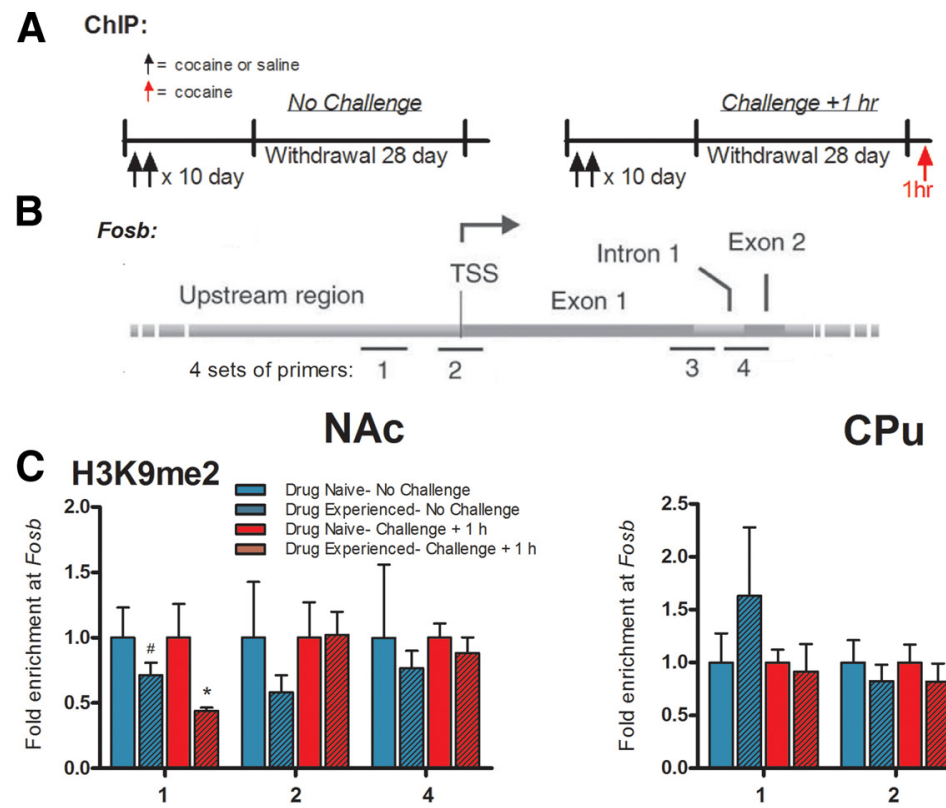

$\mathrm{CPu}$

\section{H3K4me3 and H3K27me3}
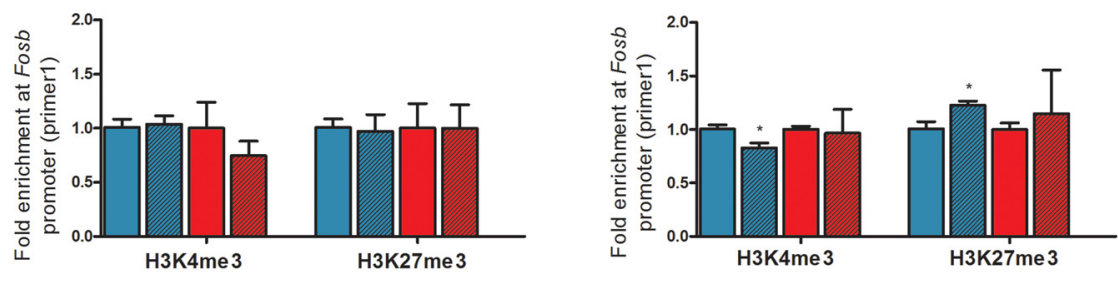

\section{E Pol II pSer5}
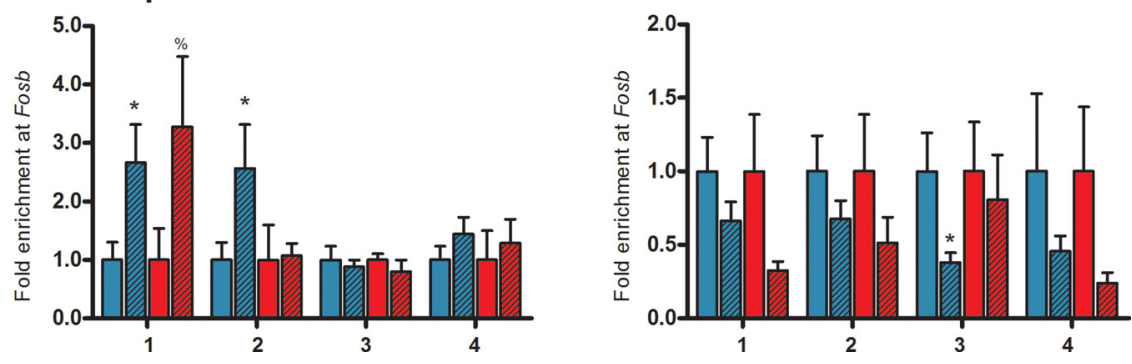

Figure 3. Effect of prior chronic cocaine exposure on epigenetic priming of the Fosb gene in NAc and CPu. $A$, Rats were injected intraperitoneally twice daily with either saline (Drug Naive) or cocaine (15 mg/kg; Drug Experienced) for $10 \mathrm{~d}$. After $28 \mathrm{~d}$ of withdrawal, animals were either not injected (Drug Naive-No Challenge) or given one injection of cocaine (15 mg/kg, i.p.) and killed $1 \mathrm{~h}$ later (Drug Experienced-Challenge $+1 \mathrm{~h}$ ) to collect NAc and CPu for ChIP analysis. B, Graphical map (not to scale) to show relative position of the four sets of primers designed upstream and downstream of the Fosb TSS: primer 1 is situated 200 bp upstream of the TSS; primer 2 is centered \pm 55 bp around the TSS; primers 3 and 4 are located 693 and 1417 bp within the Fos $b$ gene body, respectively. ChIP was performed for C, H3K9me2 using primers 1, 2, and 4; D, H3K4me3 and H3K27me3 using primer 1 only; and $\boldsymbol{E}$, Pol II-pSer5 across all 4 primers. $n=5-12$ per group; two-tailed Student's $s$ tests: ${ }^{*} p<0.05,{ }^{\%} p=0.1,{ }^{\#} p=0.2$, compared with respective Drug Naïve controls. Data are expressed as mean \pm SEM.

\section{Characterization of upstream signaling pathways in NAc and $\mathrm{CPu}$ of cocaine-experienced rats}

One possible explanation for the altered inducibility of the Fosb gene in NAc and $\mathrm{CPu}$ after a prior chronic course of cocaine is that a remote history of cocaine exposure might induce lasting changes in signaling pathways that are upstream of Fosb gene induction such that a cocaine challenge then induces the gene to an aberrant degree. To study this hypothesis, we analyzed the two transcription factors, SRF and CREB, that have been shown recently to be required for cocaine induction of $\Delta \mathrm{FosB}$ in these brain regions (Vialou et al., 2012), along with upstream protein kinases, ERK and AKT, also implicated in cocaine action (Valjent et al., 2000; Lu et al., 2006; Boudreau et al., 2009). We failed to detect any changes in total or phosphorylated levels of these various proteins that could explain the altered induciblility of Fosb observed, including no changes in SRF, CREB, or AKT (Fig. $2 B, C)$. The lack of change in pSRF and pCREB in NAc in response to a cocaine challenge is consistent with a recent report that found both induced significantly by chronic cocaine only (Vialou et al., 2012). 
In NAc and CPu of drug-naive animals, 20 min after an initial drug exposure (Fig. 2A), a single cocaine challenge decreased levels of pERK42/44 (two-tailed Student's $t$ test: $p<0.05$; Fig. $2 B, C)$. There are previous reports of increased pERK levels in these regions after acute cocaine administration (Valjent et al., 2000). This is difficult to compare to other studies examining ERK phosphorylation in NAc during withdrawal from repeated cocaine injections (Boudreau et al., 2007; Shen et al., 2009), as in our study pERK was quantified after $28 \mathrm{~d}$ of withdrawal and after a cocaine or saline challenge. Relative to drug-naive animals experiencing cocaine for the first time, reexposure to cocaine in cocaine-experienced rats, after $28 \mathrm{~d}$ of withdrawal, caused a significant increase in pERK42/44 levels in CPu (two-tailed Student's $t$ test: $p<0.05$; Fig. $2 B, C)$.

\section{Chromatin landscape at the Fosb gene promoter in NAc and $\mathrm{CPu}$ of cocaine-experienced rats}

We next investigated whether changes in Fosb gene inducibility are associated with alterations in its chromatin structure. ChIP was performed on $\mathrm{NAc}$ and $\mathrm{CPu}$ using antibodies directed against three well characterized forms of histone modifications: trimethylation of Lys 4 of histone $\mathrm{H} 3$ ( $\mathrm{H} 3 \mathrm{~K} 4 \mathrm{me} 3$ ), associated with gene activation; and $\mathrm{H} 3 \mathrm{~K} 27 \mathrm{me} 3$ and $\mathrm{H} 3 \mathrm{~K} 9 \mathrm{me} 2$, associated with gene repression. We analyzed cocaine-naive and -experienced rats after $28 \mathrm{~d}$ of withdrawal either without or with a challenge injection of cocaine, with animals examined $1 \mathrm{~h}$ later (Fig. $3 A$ ). In NAc, we found no significant changes in the binding of any of these three histone modifications to the Fosb gene promoter in the absence of a cocaine challenge, although there was a trend for reduced levels of H3K9me2 (two-tailed Student's $t$ test, $p=0.2$ compared with respective drug-naive controls; Fig. $3 B-D$ ). This effect became significant after a cocaine challenge and was specific for the proximal promoter region of the gene $(p<0.05$; Fig. $3 C$ ). While levels of $\mathrm{H} 3 \mathrm{~K} 9 \mathrm{me} 2$ are very low in some genes, the Fosb gene promoter shows appreciable levels of this mark in NAc under control conditions (data not shown) (Maze et al., 2010). In contrast, in $\mathrm{CPu}$, we found small but significant decreases in $\mathrm{H} 3 \mathrm{~K} 4 \mathrm{me} 3$ binding and increases in $\mathrm{H} 3 \mathrm{~K} 27 \mathrm{me} 3$ binding at the Fosb promoter in the absence of a cocaine challenge, effects lost after the challenge ( $p<0.05$; Fig. $3 D)$.

We next investigated Pol II binding to the Fosb gene, based on recent findings in cell culture that stalling of Pol II at TSSs, which is characterized by its phosphorylation at Ser5 in its CTD repeat region, is associated with priming of genes (see Introduction, above). We thus analyzed Pol II-pSer5 binding to Fosb at four distinct regions of the gene (Fig. $3 B$ ). This analysis revealed a significant enrichment of Pol II-pSer5 at the Fosb gene at its proximal promoter region and around its TSS in NAc of cocaineexperienced animals after prolonged withdrawal in the absence of a cocaine challenge compared with controls $(p<0.05$; Fig. $3 E)$. This enrichment was not apparent at two gene body regions of Fosb, consistent with Pol II stalling described in simpler experimental systems. Interestingly, after a cocaine challenge, Pol IIpSer5 binding still showed signs of enrichment, though no longer significantly, at the Fos $b$ proximal promoter region ( $p=0.1$; Fig. $3 E$ ), but returned to control levels at the TSS. Findings in $\mathrm{CPu}$ were more variable, with no clear pattern of Pol II-pSer5 binding observed.

\section{Discussion}

The present study provides new insight into the sustained regulation of Fosb weeks after cessation of repeated exposure to cocaine. We show that prior chronic cocaine administration renders the Fosb gene more inducible in NAc, resulting in faster accumulation of $\Delta$ FosB upon reexposure to the drug. Given the preponderance of evidence that $\Delta$ FosB induction in NAc mediates sensitized behavioral responses to cocaine (Nestler, 2008), our findings reveal a novel mechanism for the more rapid reinstatement of such sensitized responses after prolonged withdrawal. We demonstrate that the enhanced induction of $\Delta \mathrm{FosB}$ in NAc is associated with chromatin changes at the Fosb gene that would be expected to prime it for greater induction. Thus, we show increased Pol II binding to the proximal promoter and TSS regions of the gene that are present after 4 weeks of withdrawal from prior chronic cocaine administration. Such Pol II enrichment at the TSS is lost rapidly upon cocaine challenge and Fosb induction, consistent with a model in cell culture that stalled Pol II is released from TSSs upon gene activation (see Introduction, above). A cocaine challenge also induces a rapid decrease in binding of $\mathrm{H} 3 \mathrm{~K} 9 \mathrm{me} 2$ - a mark of gene repression - to the Fosb promoter. In contrast, we detected no lasting induction of several transcription factors, or of their upstream kinases, that are known to mediate Fosb induction by cocaine. These results support our hypothesis that the enhanced induction of $\Delta$ FosB in NAc is mediated via epigenetic priming of the Fosb gene and not via upregulation of upstream events.

Very different results were obtained for $\mathrm{CPu}$. There was no evidence for Pol II stalling at Fosb in cocaine-experienced rats before a cocaine challenge, although there were small but significant histone modifications consistent with gene repression: increased H3K27me3 binding and decreased H3K4me3 binding. There was also no change in upstream transcription factors or kinases consistent with reduced Fosb induction. These findings suggest that after chronic cocaine administration, epigenetic modifications serve to dampen Fosb gene inducibility in $\mathrm{CPu}$, in contrast to the priming seen in NAc. However, while these effects repress $\Delta$ FosB mRNA induction upon reexposure to cocaine, there is no loss in accumulation of $\Delta$ FosB protein. The mechanism underlying this paradox requires further investigation.

More generally, our results support a model where alterations in the chromatin landscape at specific genes in response to chronic cocaine administration serve to prime or blunt those genes for subsequent induction upon reexposure to the drug. Such chromatin changes, which can be viewed as epigenetic scars, would be missed in analyses of steady-state mRNA levels of genes. In this way, characterization of the epigenome of addiction promises to reveal fresh information about the molecular pathogenesis of the disorder, which can be mined for the development of new treatments.

\section{References}

Alibhai IN, Green TA, Potashkin JA, Nestler EJ (2007) Regulation of fosB and DeltafosB mRNA expression: in vivo and in vitro studies. Brain Res 1143:22-33.

Bataille AR, Jeronimo C, Jacques PÉ, Laramée L, Fortin MÈ, Forest A, Bergeron M, Hanes SD, Robert F (2012) A universal RNA polymerase II CTD cycle is orchestrated by complex interplays between kinase, phosphatase, and isomerase enzymes along genes. Mol Cell 45:158-170.

Boudreau AC, Reimers JM, Milovanovic M, Wolf ME (2007) Cell surface AMPA receptors in the rat nucleus accumbens increase during cocaine withdrawal but internalize after cocaine challenge in association with altered activation of mitogen-activated protein kinases. J Neurosci 27:10621-10635.

Boudreau AC, Ferrario CR, Glucksman MJ, Wolf ME (2009) Signaling pathway adaptations and novel protein kinase A substrates related to behavioral sensitization to cocaine. J Neurochem 110:363-377.

Core LJ, Lis JT (2008) Transcription regulation through promoterproximal pausing of RNA polymerase II. Science 319:1791-1792. 
Covington HE 3rd, Maze I, Sun H, Bomze HM, DeMaio KD, Wu EY, Dietz DM, Lobo MK, Ghose S, Mouzon E, Neve RL, Tamminga CA, Nestler EJ (2011) A role for repressive histone methylation in cocaine-induced vulnerability to stress. Neuron 71:656-670.

Freeman WM, Nader MA, Nader SH, Robertson DJ, Gioia L, Mitchell SM, Daunais JB, Porrino LJ, Friedman DP, Vrana KE (2001) Chronic cocaine-mediated changes in non-human primate nucleus accumbens gene expression. J Neurochem 77:542-549.

Hyman SE, Malenka RC, Nestler EJ (2006) Neural mechanisms of addiction: the role of reward-related learning and memory. Annu Rev Neurosci 29:565-598.

Kalivas PW, Volkow N, Seamans J (2005) Unmanageable motivation in addiction: a pathology in prefrontal-accumbens glutamate transmission. Neuron 45:647-650.

Lazo PS, Dorfman K, Noguchi T, Mattéi MG, Bravo R (1992) Structure and mapping of the fosB gene: FosB downregulates the activity of the fos $\mathrm{B}$ promoter. Nucleic Acids Res 20:343-350.

Lu L, Koya E, Zhai H, Hope BT, Shaham Y (2006) Role of ERK in cocaine addiction. Trends Neurosci 29:695-703.

Mandelzys A, Gruda MA, Bravo R, Morgan JI (1997) Absence of a persistently elevated $37 \mathrm{kDa}$ fos-related antigen and AP-1-like DNA-binding activity in the brains of kainic acid-treated fosB null mice. J Neurosci 17:5407-5415.

Maze I, Nestler EJ (2011) The epigenetic landscape of addiction. Ann N Y Acad Sci 1216:99-113.

Maze I, Covington HE 3rd, Dietz DM, LaPlant Q, Renthal W, Russo SJ, Mechanic M, Mouzon E, Neve RL, Haggarty SJ, Ren Y, Sampath SC, Hurd YL, Greengard P, Tarakhovsky A, Schaefer A, Nestler EJ (2010) Essential role of the histone methyltransferase G9a in cocaine-induced plasticity. Science 327:213-216.

Nechaev S, Adelman K (2008) Promoter-proximal Pol II: when stalling speeds things up. Cell Cycle 7:1539-1544.
Nestler EJ (2008) Review. Transcriptional mechanisms of addiction: role of DeltaFosB. Philos Trans R Soc Lond B Biol Sci 363:3245-3255.

Nye HE, Hope BT, Kelz MB, Iadarola M, Nestler EJ (1995) Pharmacological studies of the regulation of chronic FOS-related antigen induction by cocaine in the striatum and nucleus accumbens. J Pharmacol Exp Ther 275:1671-1680

Perrotti LI, Hadeishi Y, Ulery PG, Barrot M, Monteggia L, Duman RS, Nestler EJ (2004) Induction of deltaFosB in reward-related brain structures after chronic stress. J Neurosci 24:10594-10602.

Robison AJ, Nestler EJ (2011) Transcriptional and epigenetic mechanisms of addiction. Nat Rev Neurosci 12:623-637.

Robinson TE, Kolb B (2004) Structural plasticity associated with exposure to drugs of abuse. Neuropharmacology 47 [Suppl 1]:33-46.

Saha RN, Wissink EM, Bailey ER, Zhao M, Fargo DC, Hwang JY, Daigle KR, Fenn JD, Adelman K, Dudek SM (2011) Rapid activity-induced transcription of Arc and other IEGs relies on poised RNA polymerase II. Nat Neurosci 14:848-856.

Shaham Y, Hope BT (2005) The role of neuroadaptations in relapse to drug seeking. Nat Neurosci 8:1437-1439.

Shen HW, Toda S, Moussawi K, Bouknight A, Zahm DS, Kalivas PW (2009) Altered dendritic spine plasticity in cocaine-withdrawn rats. J Neurosci 29:2876-2884.

Valjent E, Corvol JC, Pages C, Besson MJ, Maldonado R, Caboche J (2000) Involvement of the extracellular signal-regulated kinase cascade for cocaine-rewarding properties. J Neurosci 20:8701-8709.

Vialou VF, Feng J, Robison AJ, Ku SM, Ferguson D, Scobie KN, MazeiRobison M, Mouzon E, Nestler EJ (2012) Serum response factor and cAMP response element binding protein are both required for cocaine induction of [delta]FosB. J Neurosci 32:7577-7584.

Zeitlinger J, Stark A, Kellis M, Hong JW, Nechaev S, Adelman K, Levine M, Young RA (2007) RNA polymerase stalling at developmental control genes in the Drosophila melanogaster embryo. Nat Genet 39:1512-1516. 